03

\title{
Акустические характеристики автоколебательного процесса, возникающего при взаимодействии сверхзвуковой недорасширенной струи с цилиндрической полостью
}

\author{
(C) К.Н. Волков, В.Н. Емельянов, А.В. Ефремов, А.И. Цветков \\ Балтийский государственный технический университет „ВОЕНМЕХ“ им. Д.Ф. Устинова, \\ 190005 Санкт-Петербург, Россия \\ e-mail: dsci@mail.ru
}

Поступило в Редакцию 15 октября 2019 г.

В окончательной редакции 15 октября 2019 г.

Принято к публикации 3 декабря 2019 г.

\begin{abstract}
В газоструйных излучателях высокого давления источником звуковой энергии служит кинетическая энергия газовой струи при сверхкритических перепадах между рабочим давлением и давлением окружающей атмосферы. При определенных условиях натекание сверхзвуковой струи на резонатор сопровождается мощным автоколебательным процессом с генерацией акустических волн в окружающую среду и полость резонатора. Рассмотрена модель автоколебательного процесса, возникающего при взаимодействии неизобарической струи с полузамкнутыми цилиндрическими полостями, позволяющая выделить типовые элементы газодинамической структуры формирующегося течения. Обсуждена физическая картина течения в полости газоструйного излучателя, и проведено исследование зависимости характеристик автоколебательного процесса от определяющих газодинамических и геометрических параметров.
\end{abstract}

Ключевые слова: аэроакустика, сверхзвуковая струя, генерация шума, газоструйный генератор, автоколебательный процесс.

DOI: 10.21883/JTF.2020.05.49172.345-19

\section{Введение}

Интерес к исследованию нестационарных течений обусловлен тем, что такие течения возникают во многих технологических устройствах, моделирование которых имеет большое практическое значение. Одним из интересных и сложных типов нестационарных течений являются неустойчивые течения, где наблюдаются значительные пульсации параметров, например, давления. Примером технического устройства, в котором возникают пульсации давления, является газоструйный излучатель звука, представляющий собой конструкцию, состоящую из сверхзвукового осесимметричного сопла и соосно с ним расположенной полузамкнутой цилиндрической полости (резонатора), открытым концом направленной навстречу струе. Сверхзвуковая струя, натекающая на резонатор, в зависимости от геометрических размеров системы и параметров потока реализует мощные автоколебания.

Газоструйные излучатели звука находят применение для интенсификации процессов тепло- и массообмена, а также в метрологическом обеспечении систем измерения малых динамических давлений. Достаточно широкое распространение получили газо-импульсная и звуковая очистка радиационных и конвективных поверхностей котлов и топочных установок. Результаты исследований резонансных колебаний находят применение при разработке газодинамических клапанов и газоструйных систем дозирования и впрыска в камеру сгорания контролируемых порций подготовленной топливной смеси.

В работах [1-3] изучается низкочастотный колебательный процесс взаимодействия воздушных струй с трубной полостью, когда частота процесса не превосходит акустической частоты трубы. Тепловые процессы при взаимодействии струи с полостью обсуждаются в работе [4]. Результаты исследований возникающих автоколебаний и акустических пульсаций, создаваемых взаимодействием струи с преградой, приводятся в работах [5-12]. При обтекании цилиндра, имеющего полость достаточно большой глубины, колебания головного скачка уплотнения происходят без существенного изменения его формы. Входная кромка цилиндра является местом генерации звуковых волн, которые, распространяясь вглубь полости, взаимодействуют с дном, отражаются, в результате чего образуются прямые и обратные бегущие звуковые волны, которые, складываясь, приводят к возникновению в полости стоячей звуковой волны, характеризующей резонансный процесс. Экспериментальные и численные результаты для различных каверн приводятся в работах [13-15]. Генерация тонального шума, возникающего при взимодействии сверхзвуковых струй с преградами, обсуждается в работах $[16,17]$.

Тепловые процессы в донной области обсуждаются в работах [18-20]. При достаточно большой глубине полости резонатора в ней вблизи заглушенного торца происходит интенсивное выделение тепла. К такому эффекту приводит то, что с увеличением глубины по- 
лости вблизи ее заглушенного торца возникает зона, имеющая слабый массообмен с потоком газа из сопла. Тепло, выделяющееся при периодическом прохождении по газу ударных волн, накапливается, в результате чего температура газа вблизи торца может в несколько раз превысить температуру торможения газа в сопле.

Определение зон акустического излучения, поиск максимального уровня звукового давления на основной частоте первой моды, а также эмпирических соотношений по определению зон акустического излучения приводит к значительному увеличению объема экспериментальных и численных исследований.

В настоящей работе проводится экспериментальное исследование взаимодействия сверхзвуковой струи с цилиндрической полостью и возникновения в полости автоколебательного процесса. Рассматриваются различные геометрические и режимные параметры сверхзвуковой струи, что позволяет расположить по отношению друг к другу сопло и устье трубной полости для реализации автоколебательного процесса взаимодействия струи с полостью и эффекта максимального акустического излучения.

\section{Схема измерений}

Исследование параметров газоструйных излучателей проводится на воздушном струйном стенде. Схема измерений параметров излучателя организована так, как показано на рис. 1. На горизонтальные отклоняющие пластины усилителей электронно-лучевого осциллографа ЭЛО поступает электрический сигнал с контрольного самописца давления КСД, согласованного с электродинамическим манометром МЭД. Электродинамический манометр МЭД установлен в форкамере струйного стенда и регистрирует полное давление $\left(\Delta p_{0}=p_{0}-p_{\infty}\right.$, где $p_{0}-$ полное давление, $p_{\infty}$ - давление окружающей среды). Таким образом, величина электрического сигнала КСД пропорциональна полному давлению в форкамере.

На вертикальные отклоняющие пластины усилителей осциллографа ЭЛО поступают сигналы от микрофона $(\mathrm{MФ)} \mathrm{через} \mathrm{измеритель} \mathrm{шума} \mathrm{и} \mathrm{вибраций} \mathrm{ВШВ-003} \mathrm{и}$ сигналы от датчика давления ДДИ-20 через индуктивный высокочастотный преобразователь ИВП-2. Результирующие сигналы микрофона и датчика, регистрируемые ЭЛО при организации такой схемы измерений, являются также функциями полного давления. Воздушный струйный стенд расположен в бетонном помещении, микрофон при этом размещается на расстоянии $6 \mathrm{~m}$ от излучателя. Индуктивный датчик давления ДДИ-20

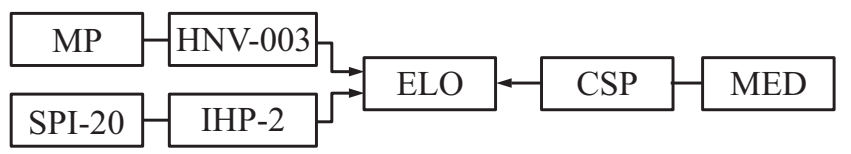

Рис. 1. Схема измерений.

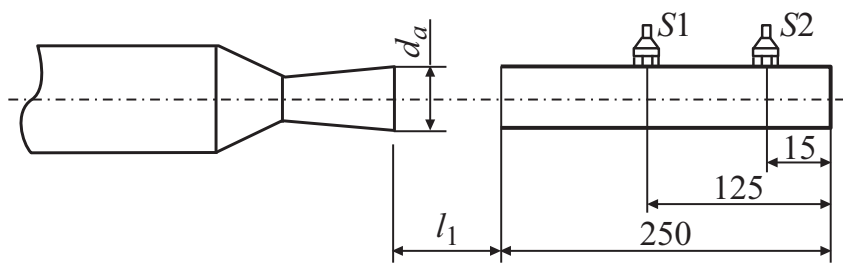

Рис. 2. Схема установки датчиков давления в трубной полости.

устанавливается в стенке трубной полости излучателя и регистрирует пульсации давления в трубной полости при взаимодействии струи с этой полостью.

Схема измерительно-регистрирующего комплекса приведена на рис. 2. В первой продольной моде датчик $S 1$ регистрирует первый подъем давления $\left(\Delta p_{2}\right)$ за проходящей мимо него ударной волной, второй подъем давления $\left(\Delta p_{5}\right)$ за отраженной от дна полости ударной волной, а затем падение давления в волнах разрежения в фазе вытекания газа из полости трубы. Датчик $S 2$, установленный ближе к дну полости, при данной временной развертке сигнала регистрирует несколько другой характер подъема давления с более короткой по времени фазой процесса за проходящей к дну полости ударной волной.

Свободная сверхзвуковая струя является источником энергии в автоколебательном процессе при ее взаимодействии с трубной полостью. Геометрическими параметрами струи выступают диаметр выходного сечения сопла $d_{a}$ и угол полураствора сопла $\theta_{a}$. Безразмерными режимными параметрами, определяющими течение в струе в рамках модели невязкого газа, являются число Маха струи на срезе сопла $\mathrm{M}_{a}$, отношение удельных теплоемкостей $\gamma$, отношение температур торможения газа струи и окружающего пространства $T_{0 i} / T_{\infty}$ и степень нерасчетности $n=p_{a} / p_{\infty}$.

Взаимосвязь акустического излучения и ударноволнового процесса в трубной полости при организации такой схемы измерений показана на рис. 3 для излучателя со следующими параметрами: $\mathrm{M}_{a}=1.5, \theta_{a}=10^{\circ}$, $d_{a}=d_{1}=35 \mathrm{~mm}, \Delta \bar{L}_{1}=L_{1} / d_{a}=54.3 \mathrm{~mm}$. Толщина стенок трубы $h=5 \mathrm{~mm}$. На рис. 3 представлены осциллограммы (левый вертикальный ряд) сигналов микрофона $I=f\left(\Delta p_{0}\right)$ в октаве $31.5 \mathrm{~Hz}$ (в этой октаве расположена частота первой продольной моды излучателя, $\left.f \sim a / 4 L_{1}\right)$ и осциллограммы (правый вертикальный ряд) сигналов датчика давления, регистрирующего пульсации давления в трубной полости на расстоянии $300 \mathrm{~mm}$ от ее устья. Одно деление по горизонтальной оси соответствует величине $\Delta p_{0}$ в $0.1 \mathrm{MPa}$. Кривые на осциллограммах построены как огибающие сигналов микрофона и датчика давления. На осциллограммах при всех $\bar{l}_{1}$ можно наблюдать существование двух зон акустического излучения. Практический интерес представляет первая зона, границы которой по давлению $\Delta p_{0}$ определяются меньшими значениями этого давления. 

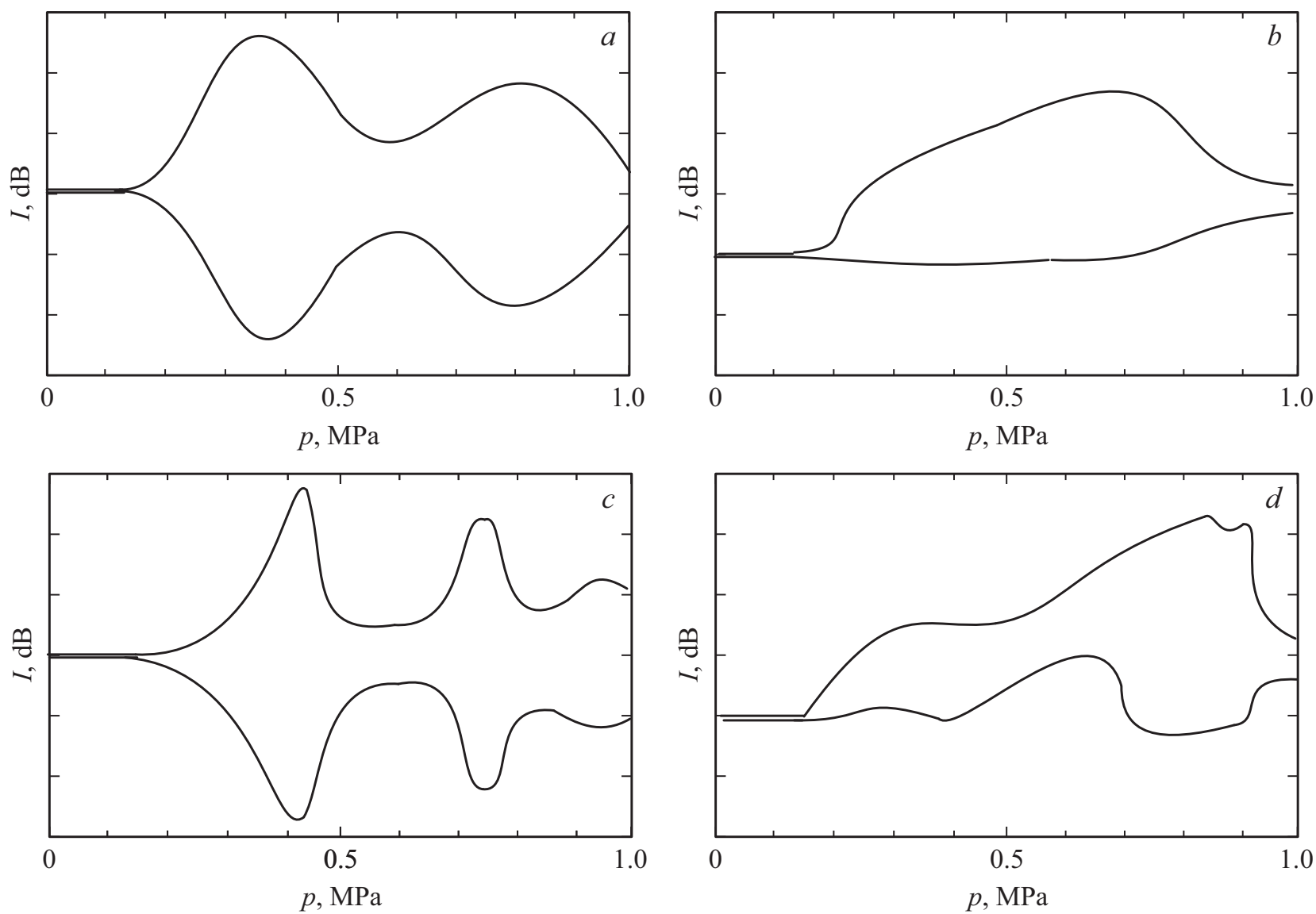

Рис. 3. Осциллограммы сигналов микрофона (слева) и датчика давления (справа) при $\bar{l}_{1}=1.43(a, b)$ и $\bar{l}_{1}=2.3(c, d)$.

С увеличением расстояния $\bar{l}_{1}$ максимум акустического излучения смещается в сторону больших давлений $\Delta p_{0}$. При этом уменьшается протяженность зон излучения по давлению $\Delta p_{0}$.

\section{Структура сверхзвуковой струи и зона акустического излучения}

Для сверхзвуковой струи по степени нерасчетности различают три режима истечения: перерасширенный $(n<1)$, расчетный $(n=1)$, недорасширенный $(n>1)$. Течение в струе условно разбивается на три участка: начальный (газодинамический), переходный, основной [21]. Неравномерность параметров по поперечному сечению струи делает нерасчетные $(n \neq 1)$ сверхзвуковые струи на газодинамическом участке наиболее приемлемыми для реализации автоколебательных процессов в трубной полости. Следует отметить, что и в случае расчетной струи $(n=1)$, истекающей из конического сопла, реализуются автоколебательные процессы в трубной полости.

Структура газодинамического участка слабонедорасширенной струи представлена на рис. 4. Сверхзвуковая недорасширенная струя идеального газа на начальном участке имеет бочкообразную форму с выпуклостью, обращенной в сторону окружающей среды. Основными

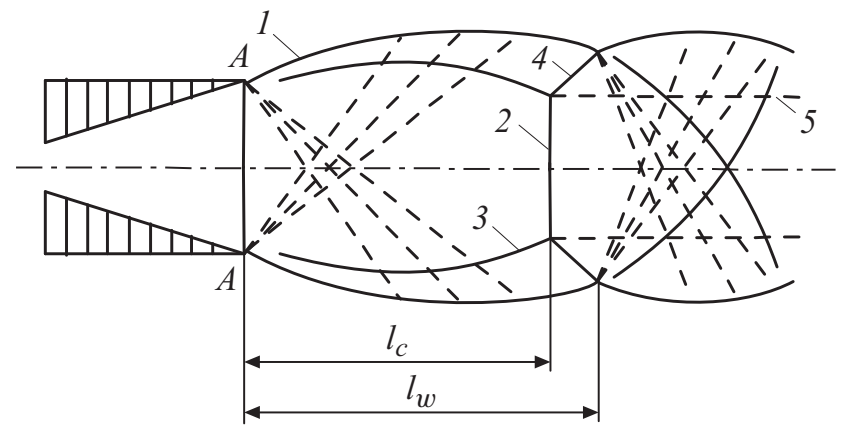

Рис. 4. Структура газодинамического участка недорасширенной струи.

элементами струи на этом участке являются: граница струи 1, центральный скачок уплотнения 2 (диск Маха), висячий скачок уплотнения 3 , отраженный скачок уплотнения 4, контактная поверхность 5, выходящая из тройной конфигурации скачков уплотнения. На рисунке указаны также положение диска Маха в свободной сверхзвуковой струе $l_{c}$ и размер первой бочки свободной сверхзвуковой струи $l_{w}$, для определения размера которых имеются различные полуэмпирические соотношения. 


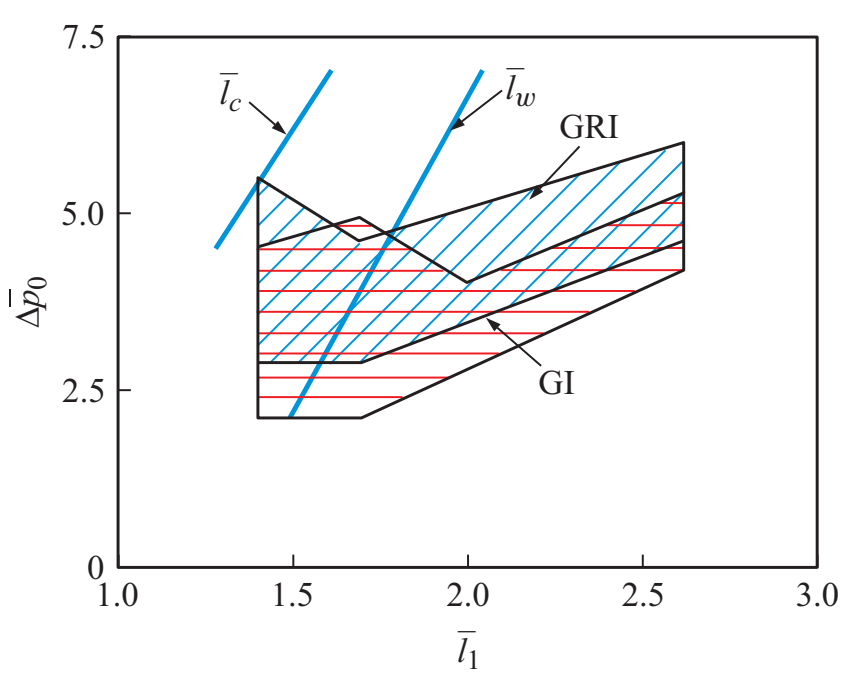

Рис. 5. Зона акустического излучения.

Такая структура струи характерна для степени нерасчетности $n>1$. При $n<2$ на газодинамическом участке может существовать несколько бочек струи, а висячие скачки при этом отражаются регулярным образом от оси струи (без образования диска Маха). Отражение скачка уплотнения от оси с образованием диска Маха называется нерегулярным отражением.

По результатам обработки осциллограмм сигналов микрофона можно построить зону акустического излучения на основной частоте первой моды в координатах $\bar{l}_{1}$ и $\Delta p_{0}$. Пример зоны акустического излучения при такой обработке показан на рис. 5.

\section{Амплитуда колебаний давления}

Графики распределения амплитуд пульсаций давления $\Delta p / p_{\infty}=\left(p_{5}-p_{1}\right) / p_{\infty}$ и частоты $f / f_{a}$ в зоне первой моды в зависимости от расстояния между соплом и устьем трубной полости приводятся на рис. 6. С удалением полости от сопла уменьшается частота первой моды и увеличивается амплитуда пульсаций давления (показания датчика давления $S 2$ ).

Зависимость амплитуды пульсаций давления от числа Маха струи в первой продольной моде показывает рис. 7. Линии 1-4 изображают зависимости давления $p_{5}, p_{c m}$, $p_{1}, p_{0}$ от числа Маха расчетной струи. Эти зависимости соответствуют точкам 1, 2 и 5 предельного цикла первой моды. Значения числа Маха $\mathrm{M}_{i}$ и давления $p_{2}$ приняты равными значениям числа Маха и статического давления в струе за центральным (прямым) скачком уплотнения, который является элементом структуры сверхзвуковой струи и присутствует перед устьем трубы в колебательном процессе. Точками обозначены величины давлений $p_{5}, p_{2}, p_{1}$, взятые из эксперимента в зоне максимальных пульсаций давления первой моды (рис. 6).
Максимальное давление в полости трубы превышает статическое давление за прямым скачком в сверхзвуковой расчетной струе (линия 2), а при $\mathrm{M}_{a}<2.3$ оказывается бо́льшим, чем полное давление струи (линия 4). Теоретические формулы дают хорошее приближение для оценки максимальных давлений у дна полости (линия 1). Экспериментально регистрируемое давление за проходящей к дну полости ударной волной $p_{2}$ ниже статического давления за прямым скачком уплотнения $p_{c m}$ (линия 2). Минимальное давление в полости ниже соответствующего расчетного давления (линия 3 ).

Расчетные зависимости давлений $p_{5}$ (линия 1 ) и $p_{1}$ (линия 2) от числа Маха сопла в третьей продольной моде $(m=1)$ приводятся на рис. 8. Значения числа Маха и давления $p_{2}$ принимаются равными значениям числа Маха $\mathrm{M}_{a}$ и статическому давлению $p_{c m}$ в расчетной $(n=1)$ струе за прямым скачком уплотнения. Из сравнения расчетных данных с экспериментальными величинами максимального $p_{5}$ и минимального $p_{1}$ давлений

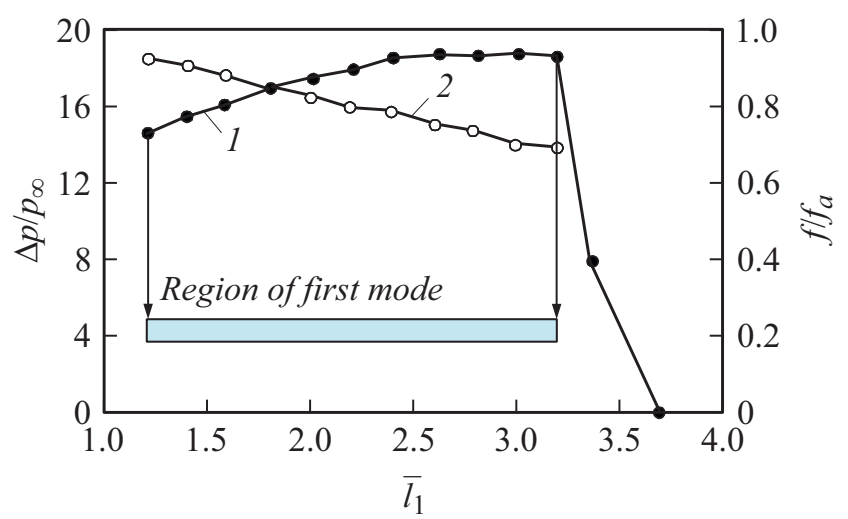

Рис. 6. Графики распределения амплитуд пульсаций давления (линия 1) и частоты (линия 2) в зоне первой моды при $n=1$ и $\mathrm{M}_{a}=3.42$.

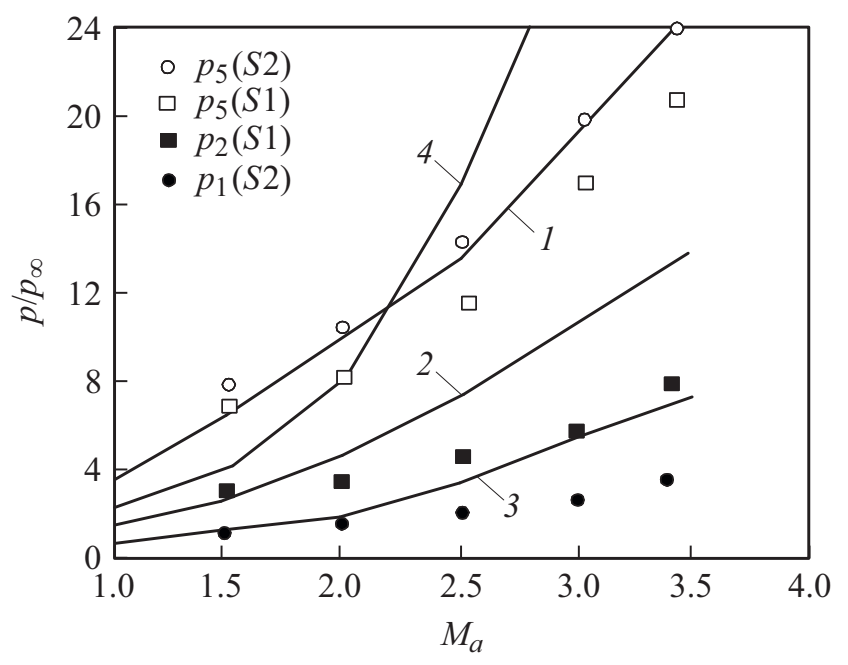

Рис. 7. Зависимость амплитуды пульсаций давления от числа Маха струи в первой продольной моде при $n=1$. 


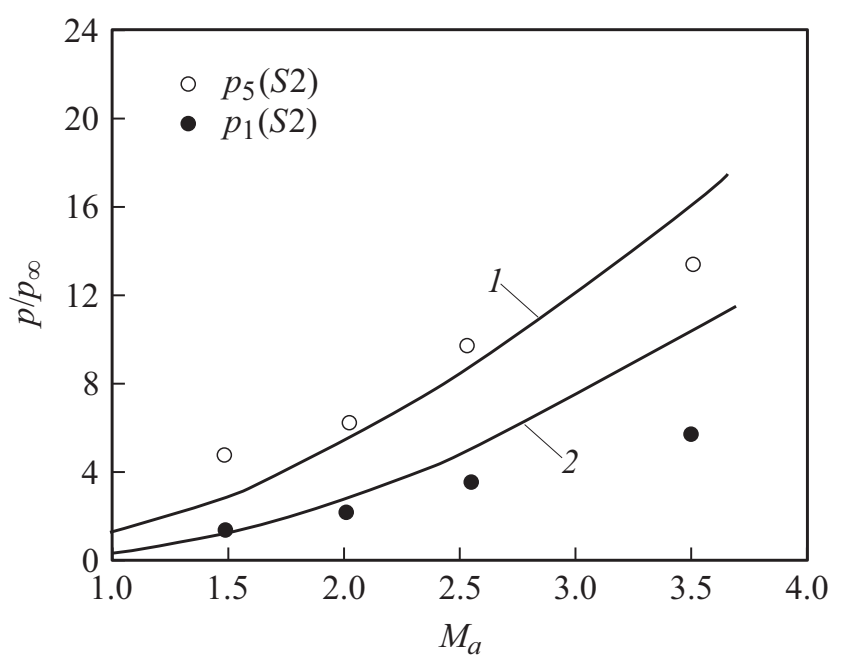

Рис. 8. Зависимость амплитуды пульсаций давления от числа Маха струи в третьей продольной моде при $n=1$.

видно, что наблюдается удовлетворительное совпадение в диапазоне по числу Маха сопла от 1.5 до 2.5.

\section{Акустические характеристики}

При изучении механизма акустического излучения газоструйных излучателей рассматривают три источника, определяющих вклад в акустическое излучение: турбулентность струи, выходящие из полости ударные волны (или волны сжатия) и пульсирующее течение между соплом и полостью. Основной вклад в акустическое излучение вносят волны сжатия.

Максимальный уровень звукового давления на основной частоте первой продольной моды можно получить в газоструйном излучателе с трубной полостью глубиной $\Delta \bar{L}_{1}=L_{1} / d_{1}$ до 5 калибров вблизи нечетных значений.

На рис. 9 построена зона акустического излучения в координатах расстояние-нерасчетность струи. Индексами $i$ и $f$ обозначены начальные и конечные координаты зоны, а через $n_{*}$ - значение нерасчетности в зоне, соответствующее максимальному значению $I_{\max }$ уровня звукового давления в октаве $31.5 \mathrm{~Hz}$. Оптимальное положение устья полости по отношению к соплу в режиме акустического излучения на основной частоте первой моды определяется размером первой бочки свободной сверхзвуковой недорасширенной струи в диапазоне нерасчетностей от 1.2 до 1.4.

Распределение уровня звукового давления по октавам при $\bar{l}_{1}=1.71$ и при максимуме акустического излучения в октаве $31.5 \mathrm{~Hz}$ показано на рис. 10. Распределение не дает полного представления о спектре акустического сигнала, дискретных составляющих и их уровнях, но позволяет сформулировать вывод о том, что в спектре наблюдается смещение акустического излучения в высокочастотную область.
Зависимость общего (суммарного) уровня звукового давления в зависимости от глубины полости при настройке на максимальный уровень звукового давления в той октаве, в которой расположена основная частота первой моды, приводится на рис. 11. Параметры излучателя следующие: $\mathrm{M}_{a}=1.5, d_{a}=25 \mathrm{~mm}$, $d_{1}=27 \mathrm{~mm}, l_{1}=60 \mathrm{~mm}$. Избыточное давление в формкамере $\Delta \bar{p}_{0}=4.2$. Уровень звукового давления существенно возрастает с уменьшением глубины полости.

Для рассматриваемых глубин полости $\bar{L}_{1}=1,3,5$, $7,9.3,18.5,38.5,76$ и соответствуют данным на рис. 11, уровни звукового давления в треть октавных полосах приводятся на рис. 12. Для глубоких полостей $\left(\bar{L}_{1}>18.5\right)$ уровень звукового давления на основной частоте первой моды ниже или сравним с уровнями звукового давления в полосах свыше $1 \mathrm{kHz}$. В диапазоне свыше $1 \mathrm{kHz}$ решающий вклад в общий уровень вносят турбулентные пульсации. Для неглубоких полостей $\left(\bar{L}_{1}<9\right)$ существенным является уровень звукового давления на основной частоте первой моды. Решающий вклад определяется волнами сжатия и пульсирующим те-

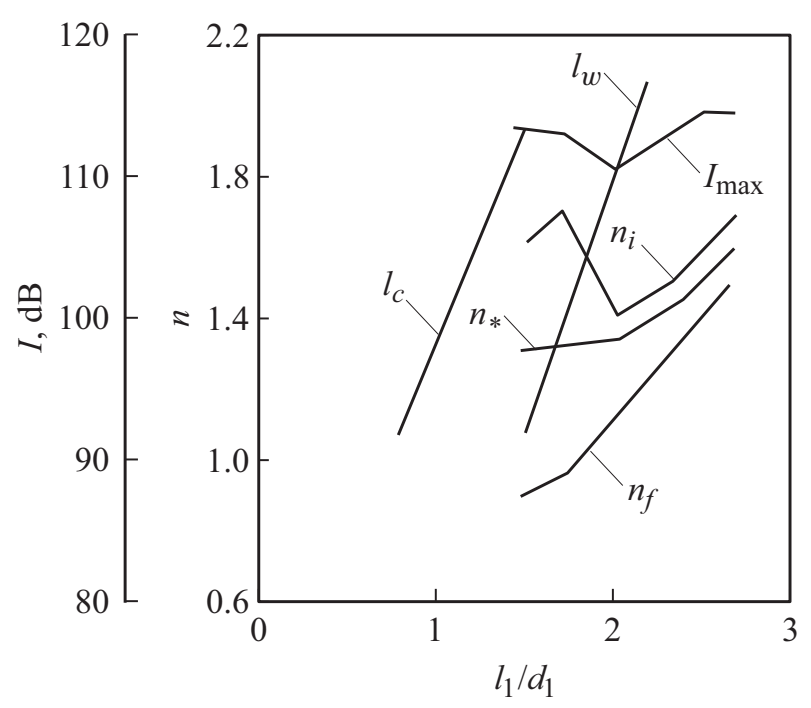

Рис. 9. Зона акустического излучения.

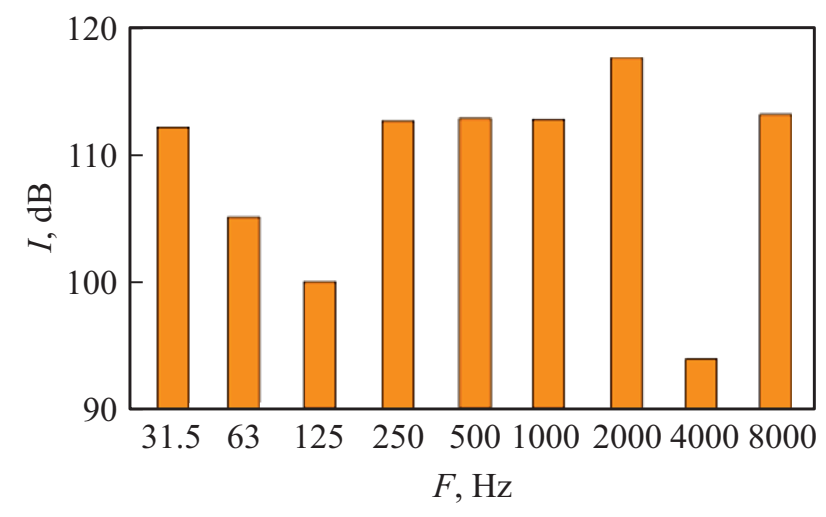

Рис. 10. Распределение уровня звукового давления по октавам. 


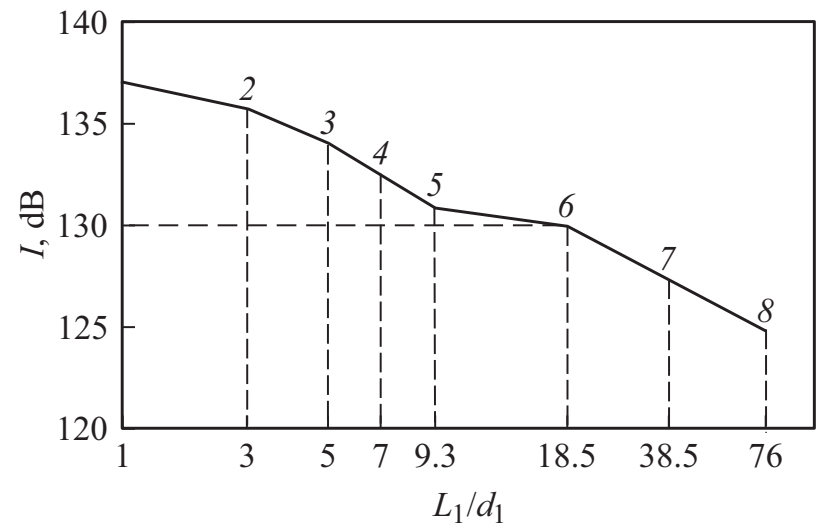

Рис. 11. Зависимость общего уровня звукового давления от глубины полости излучателя.

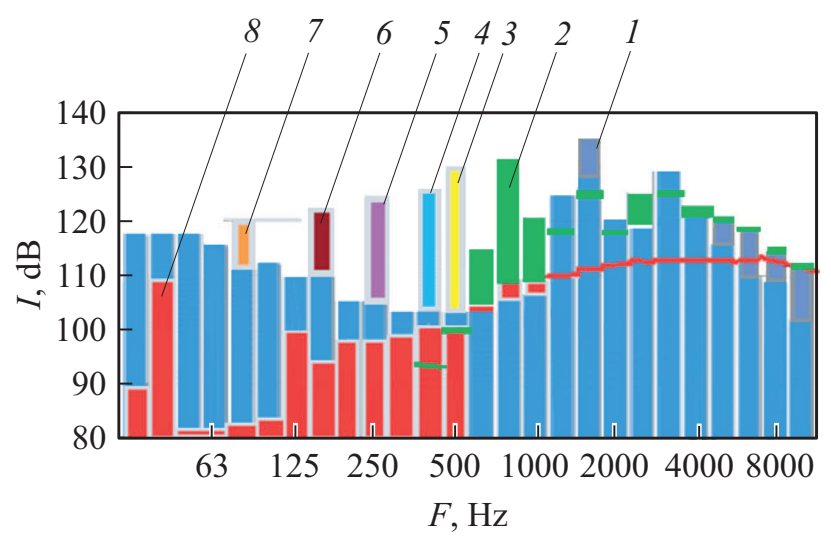

Рис. 12. Уровни звукового давления в третьоктавных полосах при $\bar{L}_{1}=1(1), 3$ (2), 5 (3), 7 (4), 9.3 (5), 18.5 (6), 38.5 (7), $76(8)$.

чением газа между соплом и трубной полостью. В спектре излучения наблюдается также второй максимум, который по частоте для глубоких полостей соответствует третьей гармонике основной частоты. С уменьшением глубины полости второй максимум смещается в сторону второй гармоники основной частоты.

Увеличение числа Маха на срезе сопла свыше 1.5 не оправдано, поскольку не приводит к увеличению уровня звукового давления и имеет следствием возрастание полного давления перед соплом.

\section{Заключение}

При взаимодействии сверхзвуковой недорасширенной струи с полостью при определенных геометрических и режимных параметрах в трубе возникают пульсации давления большой амплитуды, сопровождающиеся излучением мощных звуковых волн дискретной частоты в окружающее пространство. Для нерасчетных струй, когда давление газа струи не совпадает с давлением окружающей среды, струя образует „бочки“ (ячейки нерасчетности), и пульсирующее течение реализуется при расположении среза трубки непосредственно за диском Маха, где неоднородность потока обусловлена потерями полного давления в прямом скачке.

Описана нестационарная ударно-волновая структура течения внутри и вне резонатора, характерная для автоколебательного режима взаимодействия струи с преградой. Определены области положения среза резонатора относительно набегающей сверхзвуковой нерасчетной струи, при которых возникают сильные пульсации статического давления. Полученные данные позволяют понять природу, механизм и условия возникновения автоколебательных процессов, учесть их при разработке программ и методик экспериментальных и численных исследований аэроакустических нагрузок, а также провести их оценку. Знание характерных частот автоколебаний позволяет облегчить их выделение при испытаниях в аэродинамических трубах.

Полученные результаты могут оказаться полезными при разработке теплообменных устройств, использующих газоструйные генераторы для интенсификации тепломассообменных процессов в газовых средах (горение, смешение, коагуляция, сушка), а также для очистки разных активных поверхностей от сыпучих и иных отложений.

\section{Конфликт интересов}

Авторы заявляют, что у них нет конфликта интересов.

\section{Список литературы}

[1] Brocher E., Maresca C., Bournay M.-H. // J. Fluid Mechan. 1970. Vol. 43. P. 369-384.

[2] Brocher E., Duport E. // AIAA J. 1988. Vol. 26. N 5. P. 548-552.

[3] Braud C., Dyment A. // Phys. Fluid. 2012. Vol. 24. N 4. P. 047102.

[4] Sarohia V., Back L.H. // J. Fluid Mechan. 1979. Vol. 94. P. $649-672$.

[5] Дулов В.Г., Кузьмина В.Е., Угрюмов Е.А. Автоколебательные режимы взаимодействия струи с преградами. Гидроаэромеханика. СПб: Изд-во Санкт-Петербургского ун-та, 1999. С. 74-94.

[6] Гориков Г.Ф., Усков В.Н. // ПМТФ. 1999. Т. 40. № 4. C. $143-149$.

[7] Адрианов А.Л., Безруков А.А., Гапоненко Ю.А. // ПМТФ. 2000. T. 41. № 4. C. 106-111.

[8] Глазнев В.Н., Коробейников Ю.Г. // 2001. ПМТФ. Т. 42. № 4. C. 62-67.

[9] Dauptain A., Cuenot B., Gicquel L.Y.M. // AIAA J. 2010. Vol. 48. N 10. P. 2325-2338.

[10] Davis T.B., Kumar R. // Shock Waves. 2015. Vol. 25. N 5. P. 507-520.

[11] Hildebrand N., Nichols J.W. // AIAA Paper. 2015. N 2015-2212.

[12] Mason-Smith N., Edgington-Mitchell D., Buchmann N.A., Honnery D.R., Soria J. // Shock Waves. 2015. Vol. 25. N 6. P. 611-622. 
[13] Hamed A., Das K., Basu D. // AIAA Paper. 2002. N 2002-1118.

[14] Handa T., Miyachi H., Kakuno H., Ozaki T., Maruyama S. // AIAA J. 2015. Vol. 53. N 2. P. 420-425.

[15] Chung K.M., Lee K.H., Chang K.C. // J. Aircraft. 2016. Vol. 53. N 5. P. 1565-1567.

[16] Gojon R., Bogey C. // AIAA J. 2017. Vol. 55. N 6. P. $1792-1805$.

[17] Karami S., Soria J. // Aerospace. 2018. Vol. 5. P. 73 (16 p.).

[18] Купџов В.М., Остроухова С.Н., Филипов К.Н. // Известия АН СССР. МЖГ. 1977. № 5. С. 104-111.

[19] Купцов В.М., Филипов К.Н. // Известия АН СССР. МЖГ. 1981. № 3. C. $167-170$.

[20] Narayanan S., Bholanath B., Srinivasan $K$., Sundararajan T. // Intern. J. Aeroacoustics. 2013. Vol. 12. N 5-6. P. 557-578.

[21] Волков К.Н., Емельянов В.Н., Зазимко В.А. Турбулентные струи: статические модели и моделирование крупных вихрей. М.: Физматлит, 2014. 360 с. 